\title{
DIREITOS HUMANOS E JUVENTUDE: REPRESENTAÇÕES DA ADOLESCÊNCIA EM CONFLITO COM A LEI NO BRASIL
}

HUMAN RIGHTS AND YOUTH: ADOLESCENCE REPRESENTATIONS IN CONFLICT WITH THE LAW IN BRAZIL

\section{Luiza Eridan Elmiro Martins de Sousa', Ana Paula Fagundes Bezerra ${ }^{2}$}

RECEBIDO EM: 26/10/2016 / APROVADO EM:

DOI: $10.5902 / 2317175824611$

\section{RESUMO}

Discussões acerca da redução da maioridade penal, bem como da criação de uma justiça juvenil, vêm ganhando espaço no campo das políticas públicas voltadas para esse segmento. Seguindo essa direção, este trabalho propõe um resgate da história dos sistemas de vigilância e punição e das ações voltadas para a penalização dos adolescentes autores de atos infracionais. Por meio de uma revisão de literatura, busca-se tecer um quadro das transformações no sistema punitivo infantil brasileiro e sua consolidação enquanto sistema socioeducativo. Observou-se que no decorrer do processo histórico brasileiro, ocorreu a passagem da visão da criança e do adolescente como objetos de repressão para sujeito de direitos e, ultimamente, a inclusão destes enquanto "classe perigosa" e "sujeitos à punição", ideologia esta que acaba influindo de maneira decisiva na constituição de políticas públicas voltadas para a questão do adolescente em conflito com a lei.

Palavras-chaves: Direitos Humanos; Juventude; Adolescentes em conflito com a lei.

1 Psicóloga da Universidade Federal do Ceará no Campus de Quixadá-Ce. Graduada em Psicologia pela Universidade Federal do Ceará (2005) e Mestra pelo Mestrado Acadêmico em Políticas Públicas e Sociedade na Universidade Estadual do Ceará (2010). E-mail: luizaeridan@gmail.com

2 Graduação em Psicologia pela Universidade Federal do Ceará (2001). Mestre em Políticas Públicas pela Universidade Estadual do Ceará (2011). Docente em Psicologia no Centro Universitário Católica de Quixadá. E-mail: apaulafag@gmail.com. 
DIREITOS HUMANOS E JUVENTUDE:

REPRESENTAÇÕES DA ADOLESCÊNCIA EM CONFLITO COM A LEI NO BRASIL

\begin{abstract}
Discussions on the reduction of the criminal majority as well as the creation of juvenile justice have been gaining ground in the field of public policies aimed at this segment. According to this, this work proposes a rescue of the history of surveillance and punishment systems and of actions aimed at penalizing adolescents who commit acts of infraction. Through a literature review, it is sought to provide a picture of the transformations in the brazilian child punitive system and its consolidation as a socioeducational system. It was observed that in the course of the brazilian historical process occurred a passage of the vision of the child and adolescent as objects of repression for the subject of rights and, ultimately, an inclusion of the times "dangerous class" and "subject to punishment "This ideology has just decisively influenced the constitution of public policies aimed at a question of adolescents in conflict with a law.
\end{abstract}

Keywords: Human rights; Youth. Adolescents in conflict with the law.

\title{
1 Introdução
}

Após anos de lutas dos movimentos sociais ligados à defesa dos direitos humanos, motivadas pelo processo de redemocratização do estado brasileiro na década de 80, em 1990 promulgou-se a Lei ${ }^{\circ}$ 8.069/90, denominada de Estatuto da Criança e do Adolescente (ECA), reconhecendo todas as crianças e adolescentes como cidadãos, com direitos e deveres pessoais e sociais. A referida lei veio para assegurar a proteção integral de crianças e adolescentes, além de regular a política de atendimento social e jurídico voltadas a esse público, bem como as sanções àqueles que se envolvessem em algum ato de natureza infracional.

Essa responsabilização jurídica do adolescente pelo ato praticado já estava prevista na Constituição Federal de 1988, em seu artigo 228: "são inimputáveis os menores de dezoito anos, sujeitos às normas da legislação especial", ou seja, eles são responsabilizados pelos atos infracionais praticados e respondem legalmente, de acordo com legislação específica, o ECA.

O referido Estatuto, e o fundamento ideológico que o embasou, veio para se contrapor a um passado histórico de controle e exclusão social, substituindo o antigo Código de Menores de 1927 (reformulado em 1979), em virtude do qual as crianças e os adolescentes eram vistos sob o paradigma da situação irregular e tratados como objetos de repressão. Buscava inverter essa lógica, sob a ótica da inclusão, a partir da qual a criança e o adolescente passaram a ser considerados e reconhecidos como atores sociais e sujeitos de direitos.

Este artigo relata o percurso histórico sobre a passagem de uma ideologia calcada na objetificação da infância e da adolescência enquanto público -alvo (objeto) de práticas coercitivas, ações que encontravam seu fundamento em uma doutrina da situação irregular, para um modelo integral em que o referido público é compreendido como sujeito e, por isso, de direitos, sustentada em uma outra lógica, a do ser humano em desenvolvimento. 
O estudo se justifica e tem sua relevância na medida em que entender a história dos processos de exclusão da adolescência pobre no Brasil, desde a colonização, põe em destaque sua trajetória. Logo, investigar a adolescência, a partir das relações econômicas e sociais historicamente vigentes, propicia uma discussão sobre as origens do termo "menor" com todo o peso estigmatizante que ele carrega. Simultaneamente, evidenciam-se as políticas públicas dirigidas ao adolescente autor de ato infracional no decorrer desse processo.

\section{A passagem da punição à socioeducação}

A transição do século XIX para o século XX pode ser entendida como extremamente importante no que diz respeito à preocupação em tratar especificamente a questão da população infanto-juvenil. No Brasil, a abolição da escravatura e a proclamação da república provocaram, no rastro das grandes transformações sociais que ocorriam, mudanças também no olhar lançado sobre as crianças e os adolescentes pobres. Entretanto, preponderava a tônica higienista nas discussões e nas práticas assistenciais, pois os conceitos de saúde física e moral da família como célula social e da formação do cidadão trabalhador coincidiam com o ideal positivista republicano de "limpeza social" e higienização da pobreza. Assim, aquele que não trabalhava ou tinha uma família que não se enquadrava no modelo ideal era tido como necessitado de assistência e passível de correção, por oferecer risco social à nação que se formava (PINHEIRO, 2006).

Em um contexto mais amplo, o século XX foi marcado pelas contradições do sistema capitalista que se consolidava enquanto modo de produção, pois, ao mesmo tempo em que o capital se expandia, também ficavam evidentes as grandes parcelas da população excluídas e marginalizadas. Essa realidade histórica de mudanças, inquietações, medo das transgressões e a necessidade de reordená-las, leva "os Estados a penetrarem e interferirem mais profundamente na sociedade, através de soluções institucionais que solicitam uma obediência passiva aos cidadãos" (MANCEBO, 2002, p. 106). Com efeito, as implicações trazidas por tais mudanças, embasadas pelo neoliberalismo como arcabouço ideológico, refletiram-se não apenas na vida econômica, mas também nas diversas relações que se estabeleciam entre os homens.

A promulgação da Constituição Federal de 1988 veio atestar, no Brasil, o reconhecimento dos direitos da criança e do adolescente, algo que em nível internacional se vislumbrava desde a metade do século XX. A Carta Magna expressa o princípio da prioridade absoluta para o atendimento das crianças em todas as situações e, com o Estatuto da Criança e do Adolescente, de 1990, fundamenta o princípio da Doutrina de Proteção Integral. Até então, os códigos que legislavam sobre esse segmento populacional voltavam-se apenas àqueles em situação social de privações, de delinquência ou abandono. Não enunciavam direitos, apenas ações do Estado sobre os denominados "menores" (PINHEIRO, 2006).

Nas primeiras legislações a respeito do jovem em conflito com a lei no 
DIREITOS HUMANOS E JUVENTUDE:

Brasil, fica clara a não existência da adolescência enquanto categoria social. Essas legislações evidenciam que até meados do século XIX, pouca diferenciação havia no tratamento social e penal entre as populações jovem e adulta, a não ser reduções de pena e regulamentações sobre a idade penal.

O Código Criminal de 1830, influenciado pelo Código Francês, deixava clara a ausência de critérios relacionados à adolescência. Embora o Código tivesse adotado a responsabilidade penal aos 14 anos de idade, ele introduziu, como substituição a um critério estritamente cronológico, o critério do discernimento da ação, que pressupunha que o jovem tinha certo discernimento e conhecimento acerca de seus atos e efeitos. Esse critério foi mantido pelo primeiro Código Criminal da República, de 1890, época em que o Estado republicano brasileiro dava seus primeiros passos e vivia um contexto de intensa urbanização. Nele, a necessidade de uma maior diferenciação por faixa etária começa a tomar forma. O Código de 1890 restringiu aos nove anos de idade a responsabilidade penal e estabeleceu que, entre os nove e os catorze anos, aos menores não caberia tal responsabilidade, salvo se o juiz julgasse não terem eles agido com discernimento.

A prova do discernimento era um saber sobre a criança a quem se atribuía o ato infracional, saber construído nas relações que elas mantinham com o aparato jurídico e policial. Alguém, de algum lugar institucional, julgava o discernimento ou sua ausência. Na sua confirmação, as crianças eram levadas para as casas de correção, por um tempo determinado pelo juiz, mas que não podia ultrapassar os 17 anos. As crianças e os jovens empobrecidos, alvos do controle social, que perambulavam pelas ruas das cidades como resultado de um acelerado processo de urbanização, despertavam sentimentos manipulados por quem moldava as formas de pensar e agir, fazendo parte de imaginários e práticas que exigiam controle e coerção.

De acordo com Volpi (2001), a história moderna do tratamento dispensado ao adolescente em conflito com a lei estaria marcada pela contradição do binômio proteção-controle. A partir do crescimento desenfreado das cidades, estimulado pelo intenso desenvolvimento capitalista, percebeu-se o crescimento de uma subcategoria da infância: os abandonados-delinquentes. Eram jovens que perambulavam pelas ruas, filhos de miseráveis e ociosos, que passaram a ser encarados como categoria perigosa. Enquanto a socialização da infância ficava a cargo das famílias e da escola, os primeiros tribunais de menores teriam surgido para suprir as "carências" de socialização dos abandonadosdelinquentes. Escolas, colônias agrícolas e fábricas não eram instituições suficientes para enfrentar o crescente número de "vagabundos" que ocupavam as ruas das cidades. A instituição policial era central no enfrentamento às tendências anti-sociais dos jovens que perambulavam pelos caminhos destinados às "famílias de bem". Nesse contexto, ganhou forma e conteúdo a doutrina da situação irregular, que norteou por quase todo o século $X X$ as ações repressivas e arbitrárias do Estado sobre as crianças e os adolescentes, principalmente 
de classes populares, então denominados "menores", pois eram eles os que se considerava que viviam de forma irregular.

Os autores Mendez \& Costa, na obra Das necessidades aos direitos, de 1994, tecem a trajetória histórica da construção do conceito e representação de criança e de seu controle. Ao longo do século XX, a categoria "menor" foi se constituindo como questão social, deixando de se referir apenas à idade para designar uma situação social marcada pela pobreza, pelo abandono e pela marginalidade. Em 1923, foi criado o primeiro tribunal brasileiro de menores, que tratava de julgar os jovens autores de crimes. $O$ primeiro juiz de menores da República, Mello Matos, atuou decisivamente para a promulgação, em 1927, do novo Código de Menores, que levou seu nome. Este dispunha que nenhum menor de 18 anos, não importando o ato infracional, seria recoIhido à prisão comum destinada aos adultos. Por sua vez, o menor de 14 anos não seria submetido a nenhum processo penal.

Ainda segundo os autores citados, como reflexo das lutas internacionais pelos direitos infanto-juvenis, o Código de Mello Matos inovou com leis de assistência, proteção e tutela aos menores. A forma como se daria tanto a assistência quanto a proteção dependia da situação social. Se abandonada, pervertida ou na iminência de ser, a criança era encaminhada à asilos, casas de educação ou à famílias substitutas. Em qualquer hipótese, o tempo de internação se esgotava aos 21 anos de idade. Aqueles entre 14 e 18 anos que praticavam violação penal eram submetidos a processos especiais, embora não especificados, distintos dos aplicados aos adultos.

Em 1940 foi promulgado o Código Penal brasileiro, no qual se estabeleceu a idade penal: 18 anos. Já o Código de 1979 destinou-se àquelas crianças e adolescentes que se encontravam em situações tidas como irregulares, traduzidas, segundo Mendez \& Costa (1994), como situações de perigo que poderiam levar à uma marginalização mais ampla, visto que o abandono moral e material era algo próximo da criminalidade. Um dos resultados da utilização de definições e associações entre pobreza e criminalidade foi uma cruel marginalização da pobreza, já que ao se definir a irregularidade partiu-se do pressuposto da regularidade, baseada em um ideal de família e de juventude identificados nas camadas média e alta da sociedade.

Com uma visão deficitária vinculada às classes menos favorecidas e encarando a pobreza como principal causa da criminalidade juvenil, as medidas sugeridas e aplicadas não diferenciavam crianças e adolescentes autores de ato infracional daqueles submetidos a situações de miséria e abandono. Controlar a infância e a adolescência era controlar os pobres e minimizar seu potencial de perigo à sociedade.

Por outro lado, o que ficou formulado como Doutrina da Situação Irregular e a quem ela se refere já aparecia no Código de Mello Matos, embora tal expressão ainda não tivesse sido formulada. Ela foi proposta pelo professor Allyrio Cavallieri durante o processo de elaboração do Código de Menores de 1979, em substituição às expressões que denegriam o menor, tais como "delinquente", 
DIREITOS HUMANOS E JUVENTUDE:

REPRESENTAÇÕES DA ADOLESCÊNCIA EM CONFLITO COM A LEI NO BRASIL

"infrator", "exposto", etc. Tal doutrina foi, sem dúvida, um avanço de ordem política, cultural e jurídica em relação à situação anterior, pautada pela doutrina do direito penal do menor. Não se dirigiria ao menor apenas quando este cometesse um ato de delinquência, como fazia o direito penal, mas também quando se encontrasse em situação de privação econômica, de abandono moral e físico. Não obstante o avanço em relação às legislações anteriores, a Doutrina da Situação Irregular não reconhecia os direitos universais das crianças, que já haviam sido enunciados pelas Organizações das Nações Unidas (ONU) na Declaração Universal dos Direitos da Criança, de 1959. A Doutrina de Proteção Integral, que mais tarde inspiraria o Estatuto da Criança e do Adolescente, foi enunciada pela primeira vez na Declaração de 1959 (MENDEZ \& COSTA, 1994).

Todavia, foi com o processo de redemocratização, nos anos 1980, que se começou a fazer parte da pauta política a questão da criança e do adolescente como prioridade e sujeito de direitos. $\mathrm{O}$ artigo 227 da Constituição Federal de 1988 definiu a criança como prioridade absoluta e exigiu uma lei específica para regulamentar seus direitos, dando origem ao Estatuto da Criança e do Adolescente, em 1990. A partir de então, os direitos de crianças e adolescentes seriam enunciados, portanto, exigíveis de serem cumpridos, além de serem universais, isto é, não se dirigiam a determinadas crianças, como os códigos de menores anteriores faziam. Todas as crianças e adolescentes passaram a ser consideradas seres em peculiar condição de desenvolvimento e sujeitos de direitos, o que implica ter a proteção da ordem jurídica para sua efetivação. Não importa qual a condição ou situação social em que se encontra a criança, como determina o artigo $3^{\circ}$ do Estatuto da Criança e do Adolescente:

A criança e o adolescente gozam de todos os direitos funda-
mentais inerentes à pessoa humana, sem prejuízo da proteção
integral de que trata esta Lei, assegurando-se lhes, por lei ou por
outros meios, todas as oportunidades e facilidades, a fim de lhes
facultar o desenvolvimento físico, mental, moral, espiritual e so-
cial, em condições de liberdade e de dignidade. (BRASIL, 1990).

Além de conferir direitos fundamentais e sociais às crianças e adolescentes, o ECA inaugura uma mudança no trato do adolescente em conflito com a lei. As medidas previstas nesses casos, por serem socioeducativas, diferem das penas criminais no aspecto predominantemente pedagógico e na duração, que deve ser breve. Isso significa que adolescentes não podem responder pelos delitos que praticarem, ou serem responsabilizados criminalmente perante a legislação penal comum e, sim, com base nas normas do Estatuto próprio. E isso também significa dizer - ao contrário do que apregoam algumas parcelas da população, que criam o mito da impunidade em virtude das regras protecionistas do ECA - que os adolescentes respondem, sim, pelas infrações que porventura cometam, mas o fazem tendo em vista o caráter peculiar do adolescente como pessoa em desenvolvimento. 
A formulação do Estatuto, determinando o compromisso da sociedade brasileira em promover a valorização e defesa dos direitos de crianças e adolescentes, importou em um significativo avanço no que diz respeito à representação e ao lugar da infância e da juventude dentro da sociedade. Tais conquistas formais-legais representaram a possibilidade de novo tratamento às demandas deste público. No entanto, apesar dos avanços na garantia de direitos, ainda vive-se o dilema de efetivá-los. Por um lado, há um arcabouço jurídico de garantias e, por outro, a permanência de situações e comportamentos sociais que negligenciam e ferem os direitos da infância e adolescência.

Neste sentido, as medidas socioeducativas, enquanto ação pública, além do entendimento do "público-alvo" como beneficiário das políticas, precisam promover formas de interação, de parcerias, de avaliação constantes das práticas efetuadas e atentar para o fato de que, historicamente, os setores dirigentes vêm impondo práticas socioeducativas que mais reproduzem e conservam interesses do que transformam a sociedade e a vida dos adolescentes. Na maioria das vezes, a população não participa da construção das políticas públicas, muito menos de sua execução, e a ela não é perguntado sobre como devem funcionar ou aos interesses de quem devem atender.

Se, por um lado, a promulgação do Estatuto da Criança e do Adolescente (ECA) e do SINASE representam avanços e conquistas na área dos direitos dos adolescentes a quem foi atribuída autoria de ato infracional, por outro, instalaram dúvidas e problematizações aos gestores e profissionais que trabalham diretamente no atendimento aos adolescentes em cumprimento de medidas socioeducativas [...] A noção de socioeducação surgiu com a implementação das medidas socioeducativas normatizadas pelo ECA, o qual contempla a organização estrutural e o funcionamento das instituições de atendimento, mas deixou uma lacuna quanto à compreensão da socioeducação que pudesse se materializar em intervenções consistentes e promotoras do desenvolvimento dos adolescentes (BISINOTO, et al 2015, p. 577).

Logo, é tido como imprescindível que a população e o governo reconheçam a necessidade de cooperação para o enfrentamento das demandas da violência, principalmente aquelas que colocam a criminalidade como única via de possibilidade para o jovem, em especial o de camada popular. Trata-se não apenas de ação propriamente dita, mas de uma reiteração simbólica permanente da vontade de todos de compartilharem uma existência comum.

\section{Juventude: vítima e algoz da violência}

A juventude, seu conteúdo, duração e significação, só pode ser entendida de forma cultural e histórica. Nascida, enquanto campo de intervenção, na sociedade moderna ocidental, particularmente no século $X X$, é consequência do desenvolvimento do capitalismo, mais especificamente do momento em que crianças e adolescentes passam a deixar o trabalho nas indústrias por causa do excesso de mão de obra, ocasionado pelo intenso processo de urbanização. 
DIREITOS HUMANOS E JUVENTUDE:

A modernização cada vez mais acelerada das relações de produção capitalista impôs a necessidade da especialização da força de trabalho. Nesse processo, a escolarização adquire um status crucial, e o ensino é então prolongado cada vez mais. Consequentemente, a entrada do jovem no mundo do trabalho vai sendo adiada, e um espaço entre a infância e a vida adulta vai se configurando. Esse processo atinge inicialmente os jovens da aristocracia e da burguesia e, apenas mais tarde, estende-se às camadas populares (ÁRIES, 2008).

No entanto, essa fase de transição entre uma idade não economicamente produtiva e outra economicamente produtiva, é vivenciada de diversas maneiras, não só em sociedades distintas, mas em mesmas sociedades, apesar de que, em alguma medida, o modelo aristocrata-burguês de representar e vivenciar a juventude ainda persiste e parece funcionar como padrão ideal de vivência da condição juvenil (ABRAMO \& BRANCO, 2005). Ainda assim, prefere-se falar em juventudes, pois tem-se que os jovens são os mais diversos, apesar da significação e da representação dessa faixa etária numa sociedade ocidental moderna ser muito similar. Como assinalam Abramo \& Branco (2005):

Se há tempos atrás todos começavam seus textos sobre juventude citando Bourdieu, alertando para o fato de que a juventude poderia esconder uma situação de classe, hoje o alerta inicial é o de que precisamos falar de juventudes, no plural, e não juventude, no singular, para não esquecer as diferenças e as desigualdades que atravessam essa condição. (...). Agora a pergunta é menos sobre a possibilidade ou impossibilidade de viver a juventude, e mais sobre os diferentes modos como tal condição é ou pode ser vivida (p. 44).

Da mesma forma, a violência é uma construção social e, por mais que se desdobre em vários tipos (física, simbólica, psicológica etc.), o que dela resulta, na realidade, é uma representação social construída por meio dos fatos que ocorrem no cotidiano. Crime e violência são conceitos criados e que atravessam discursos e representações que, na modernidade, suscitam a associação perversa entre violência e pobreza. As violências de fato existem, e é cada vez mais crescente o envolvimento de adolescentes em ações (e relações) violentas, seja como vítimas quanto como atores. Entretanto, é essa representação da criminalidade hoje associada à juventude e à pobreza que traz a retórica de que a juventude é a própria representação do mal, tornando-se um desafio às políticas públicas voltadas a este segmento mudar essa retórica e construir além de novos discursos, novas práticas.

Dados do Fundo das Nações Unidas para a Infância - Unicef (2006) revelam que $45 \%$ dos adolescentes e jovens no Brasil são pobres, enquanto que, na população em geral, o índice é de $34 \%$. A condição extrema de pobreza atinge hoje $12,2 \%$ dos 34 milhões de jovens brasileiros, membros de famílias com renda per capita de até $1 / 4$ do salário mínimo, totalizando um índice de 4,2 milhões de jovens extremamente pobres. Acrescenta-se a esta condição de pobreza, a falta de qualificação e formação escolar, uma vez que $67 \%$ desses jovens não concluíram sequer o ensino fundamental e 30,2\% não trabalham e não estudam. 
Ainda nesta reflexão, estudos da Unicef (2002) apresentam índices de que entre as crianças negras ou pardas, a pobreza chega a $57,7 \%$ e, entre as indígenas, a $71 \%$. Uma criança pobre tem três vezes mais chances de morrer antes dos cinco anos de idade do que uma criança rica; 21 vezes mais chances de não ser alfabetizada; 30 vezes mais chances de morar em uma casa sem esgoto e 68 vezes mais chances de não ter um eletrodoméstico básico, como geladeira. Para esse estudo, a desigualdade social é apontada como uma das maiores causas da violência entre jovens de 15 e 24 anos.

A população de jovens cada vez mais é ameaçada, conforme dados do Mapa da Violência - Os jovens do Brasil, lançado pela Faculdade Latino Americana de Ciências Sociais - FLACSO - e cuja última versão data de 2015. Analisando dados de 2013, a pesquisa atesta que quase metade das mortes de adolescentes de 16 e 17 anos no Brasil tiveram como causa o homicídio, e 10,3 adolescentes são assassinados por dia no país. As mortes por causas externas cresceram $496 \%$ de 1980 a 2013, segundo a pesquisa. Na faixa de 16 e 17 anos, a taxa de mortalidade ficou em 54,1 homicídios por 100 mil adolescentes em 2013, um aumento de $2,7 \%$ em relação a 2012 e de $38,3 \%$ na década. O perfil das vítimas revela que a maioria (93\%) é do sexo masculino, tem de quatro a sete anos de estudo $(62 \%)$ e tem quase três vezes mais chance de ser negra do que branca. As armas de fogo são os principais instrumentos utilizados nas agressões $(81,9 \%)$.

Observa-se que, mesmo que a lei lhes garanta o status de sujeito de direito, os jovens ainda amargam certa invisibilidade social, que fica clara quando constata-se a debilidade das políticas públicas dirigidas a essa faixa etária da população. Para o adolescente da classe média e alta, esse período talvez represente menos risco social, haja vista a teia de proteção forjada pelas instituições (família, escola, sociedade) às quais está ligado. $O$ jovem das classes menos abastadas sofre com as condições adversas do meio, além de sentir a pressão pela busca da independência financeira.

No Brasil, as políticas públicas para a juventude só encontraram caminho para a consolidação de um plano nacional de políticas para essa faixa etária em 2004, quase vinte anos após a Organização das Nações Unidas (ONU) ter instituído o ano de 1985 como o Ano Internacional da Juventude e, dez anos depois, propor aos países membros a adoção de uma estratégia internacional para enfrentar os desafios atuais e futuros da juventude (SILVA \& ANDRADE, 2009). Em 2005 foram criados o Conselho Nacional de Juventude e a Secretaria Nacional da Juventude, para no ano seguinte se consolidar a Política Nacional de Juventude.

Segundo Abramo (1997), a juventude tem sido alvo de discussões, muitas destas relacionadas aos "problemas sociais", como violência, crime, delinquência juvenil, drogadição, etc. As políticas públicas para jovens estão "tomando os jovens eles próprios como problemas sobre os quais é necessário intervir, para salvá-los e reintegrá-los à ordem social" (p. 26). Inseridos neste contexto, os adolescentes acabam por incorporar a visão, constantemente reforçada e reproduzida, de seres suspeitos e extremamente perigosos. É como se neles 
DIREITOS HUMANOS E JUVENTUDE:

estivessem as marcas de potencialmente perigosos, agressivos e violentos. E é a partir de tais percepções que eles constroem e firmam suas identidades, pela perspectiva da violência e da exclusão.

O medo à desordem e à perda da vida e das propriedades, um grande descrédito na polícia e na justiça podem transformar a insegurança e o temor difusos em acusações contra segmentos sociais ou grupos específicos de sujeitos de quem se desconfia, que não são reconhecidos como iguais, ou seja, não são portadores da mesma humanidade que reconheço em mim e nos meus iguais. São, por definição, portadores de características desabonadoras, de traços de caráter indesejáveis, de um potencial de violência que os torna pouco humanos (MELLO, 1999, p. 135).

Os dados sobre a condição juvenil revelam a premente necessidade do aprofundamento do debate e da execução de políticas públicas para a juventude, principalmente dos sistemas de vigilância e punição, e das ações voltadas para a penalização dos adolescentes autores de atos infracionais. São dados que mostram ser este um campo repleto de conflitos, de tensões, envolvendo temáticas tão indispensáveis como violência, punição, repressão e educação, políticas públicas e participação cidadã. É relevante refletir acerca da história que coloca o jovem como alvo de políticas repressivas e categoria potencialmente perigosa, e a ideologia que sustenta esses (pre)conceitos e estigmas interfere de maneira decisiva na constituição do aparato jurídico e das políticas públicas voltadas para a questão do adolescente em conflito com a lei.

Assinala Cuneo (2005) que a lei, uma vez legitimada pelo Estado, não assegura a resolutividade da questão problematizada, uma vez que é preciso dispor de condições para que o cumprimento e aplicabilidade da mesma sejam assegurados. Ou seja, a normativa legal depende de estrutura técnica e financeira para que seja efetivada, depende de investimento, precisa deixar a condição abstrata e documental e inserir-se na prática. Pressupõe-se desta forma que, se a lei em congruência com a prática assegurava a plena garantia dos direitos das crianças e adolescentes estabelecidos no ECA, muitos problemas sociais seriam evitados, muitas infrações deixariam de ser cometidas, sobretudo delitos contra o patrimônio.

A aplicabilidade da lei, na área da infância e adolescência, exige atenção prioritária da sociedade, através de suas instituições, mormente a família e o Estado, para a garantia de políticas públicas eficazes no atendimento às demandas da população infanto-juvenil, sobretudo no que se refere à educação formal, profissionalização ou iniciação ao trabalho, saúde, lazer e condições de moradia. É preciso assegurar recursos públicos e investimento público-privado para que sejam consolidadas essas políticas sociais, pressupondo assegurar condições dignas de sobrevivência a todas as crianças e adolescentes brasileiros.

A efetivação de uma rede de atendimento, integrando os órgãos do Sistema de Segurança, o Sistema de Justiça, o Sistema de Atendimento (Assistência Social, Conselho Municipal dos Direitos da Criança e do Adolescente, Conselho Tutelar, entidades prestadoras de serviço...) e a sociedade em geral, faz-se necessária 
para garantir os direitos ao adolescente infrator, pressupondo sua consequente reinserção na vida social. Acredita-se que a viabilização e execução de políticas públicas que reduzam a concentração de renda, a exclusão, o desemprego e as desigualdades sociais representam alternativas eficazes diante do problema do ato infracional, em detrimento de iniciativas paliativas de institucionalização.

Para uma juventude construída socialmente, a mobilização dos recursos e das potencialidades que o jovem possui irá depender sobremaneira das alternativas abertas a ele, seja por sua inserção social, seja pelas posições que ocupam ou pelos caminhos oferecidos/negados em sua trajetória. Apesar de vivermos em uma cultura que enaltece os ideais de juventude, que glorifica o eterno frescor juvenil, sua beleza, força física e disposição, as políticas formuladas para os jovens ainda são precárias no que diz respeito a proporcionar a eles seu real lugar de sujeito de direito.

\section{Considerações finais}

A problemática do ato infracional exige que se reflita a partir da complexidade de fatores que o circundam, uma vez que não basta insistir em atitudes saudosistas de uma sociedade livre e segura, aumentando os muros das casas, a blindagem dos carros, reivindicando o sistema de pena de morte e a redução da idade penal, o aumento dos presídios, a intensificação e aumento de segurança pública e particular. É preciso promover propostas alternativas que afastem as crianças e adolescentes da criminalidade, reivindicar políticas públicas de amparo à população infanto-juvenil, dispondo de espaços de lazer e profissionalização que garantam a proteção social que o ECA estabelece.

A prática de atos infracionais por jovens pode ser interpretada como um processo adaptativo ou como forma de reação à condição de exclusão que atinge a maioria dos jovens brasileiros, exclusão que, embora esteja articulada com a pobreza produzida historicamente, se caracteriza, principalmente, pelos recalcamentos em vários setores da vida social e política. Onde falta a palavra, instala-se a violência. É preciso, portanto, reconhecer que o delito também é uma produção social, seja ele praticado por jovens ou adultos.

É importante ressaltar que apenas a lei não garante o direito, ou seja, a existência da lei não significa sua efetividade prática. É o que ocorre com a maioria dos adolescentes autores de ato infracional, na medida em que se tornam alvo do sistema de justiça somente pela via da infração, e não pela pressuposição de serem cidadãos de direito, ainda que previstos em lei, ou muitas vezes só tem acesso a construção da cidadania quando se torna um socioeducando.

Este desafio convoca a todas as pessoas que acreditam no potencial transformador da juventude, sobretudo daqueles marcados pela autoria de ato infracional, em razão de que é possível mudar essa realidade, com o intuito de construirmos uma sociedade que assegure políticas públicas eficazes e garanta realmente os direitos em prol da qualidade de vida dos seus cidadãos. 
DIREITOS HUMANOS E JUVENTUDE:

REPRESENTAÇÕES DA ADOLESCÊNCIA EM CONFLITO COM A LEI NO BRASIL

\section{Referências}

ABRAMO, H. W. Considerações sobre a tematização social da juventude no Brasil. Revista Brasileira de Educação. São Paulo, ANPED, n 5, p. 25-36, 1997.

ABRAMO, H. W. e BRANCO, P. P. M. (orgs.) Retratos da juventude brasileira: análises de uma pesquisa nacional. São Paulo: Editora Fundação Perseu Abramo, 2005.

ARIÉS, P. História social da criança e da família. $2^{\text {a }}$ ed. Rio de Janeiro: LTC, 2008.

BISINOTO, C., OLIVA, O. B., ARRAES, J., GALLI, C. Y., AMORIM, G. G. de, STEMLER, L. A. de S. Socioeducação: origem, significado e implicações para o atendimento socioeducativo. Psicologia em Estudo, Maringá, v. 20, n. 4, p.575-585, out./dez. 2015

BRASIL. Constituição da República Federativa do Brasil. Brasília: Senado Federal, 1988

BRASIL. Estatuto da criança e do adolescente. Brasília: Senado Federal, 1990.

CUNEO, M. R. Inimputabilidade não é Impunidade. Derrube esse Mito. Diga não à Redução da Idade Penal. Revista Igualdade, v. 9 n.31, pp.22-37, 2001.

MANCEBO, D. Modernidade e produção de subjetividades: breve percurso histórico. Psicologia Ciência e Profissão, v. 22, n. 1, p. 100-111, 2002.

MELLO, S. L. de. A Violência Urbana e a exclusão dos jovens. SAWAIA, B. As Artimanhas da exclusão. Petrópolis: Vozes, 1999.

MENDEZ, E. G.; COSTA, A. C. G. Das necessidades aos direitos. São Paulo: Editora Melhoramentos, 1994.

PINHEIRO, A. Criança e Adolescente no Brasil: Porque o Abismo entre a Lei e a Realidade. Fortaleza: Editora UFC, 2006.

SILVA, E. R. A. de; ANDRADE, C. C. de. A política nacional de juventude: avanços e dificuldades. In: CASTRO, J. A.; AQUINO, L.; ANDRADE, C. C. de (Orgs.). Juventude e políticas sociais no Brasil. Brasília: IPEA, 2009. p. 41-69.

SISTEMA NACIONAL DE ATENDIMENTO SOCIOEDUCATIVO - SINASE. Brasília, 2006.

UNICEF. Situação Mundial da Infância 2002. Brasília - DF.

UNICEF. Situação Mundial da Infância 2006. Brasília - DF.

VOLPI, M. (org). Sem liberdade, sem Direitos: a privação de liberdade na percepção do adolescente. São Paulo: Cortez, 2001.

WAISELFISZ J. J. Mapa da Violência - Adolescentes de 16 e 17 anos no Brasil. Rio de Janeiro: Faculdade LatinoAmericana de Ciências Sociais - FLACSO, 2015. 